\title{
Research on the Preparation Process of New Animal Glue Binder Used in Foundry
}

\author{
LIU Wei-hua ,Wang Tianshu , LI Ying-min, HUO Wen-hui \\ School of Materials Science and Engineering, Shenyang University of \\ Technology, China,Shenyang
}

\begin{abstract}
Keywords: sand binder; animal glue; alkaline decomposition; modification; mechanism of modification.

Abstract. A new sand binder system cured by heat is prepared by alkaline decomposition and modification on animal glue binder. To improve some shortages of animal glue such as agglomeration at normal temperature and a low efficiency, an alkaline decomposition process is selected firstly. With the addition of modifiers, binder is modified by copolymerization,esterification to get a high strength. In the alkaline decomposition, a good proportion between animal bone glue and water is selected as followed: $5: 6, \mathrm{NaOH}$ is used as the catalyst and its addition is $5 \%$ to the amount of animal glue, the temperature of alkaline decomposition is $55^{\circ} \mathrm{C}$ and the period of time is $25 \mathrm{~min}$.In the modification, some modifiers are selected as :animal glue: glycerin: dextrin : glycol $=100: 10: 10: 10$.The modification reaction temperature is $75^{\circ} \mathrm{C}$ and the modification reaction time is $90 \mathrm{~min}$. when heated at $200^{\circ} \mathrm{C}$ for $20 \mathrm{~min}$, the strength of binder can be built up well. With a addition of $3 \%$ to sand, the strength of binder can be $2.63 \mathrm{MPa}$ which is high enough to meet the requirement of core-making in foundry. At last, the modification mechanism of animal glue binder is analyzed in theory and the modified binder is characterized by IR..
\end{abstract}

\section{Introduction}

It is well known, many kinds of organic binders are used each year in foundry industry, such as the phenlic formaldehyde resin, the furan resin, etc. Some of the constituents of the organic binders are very harmful to the environment and workers ${ }^{[1]}$, therefore, the research on the new binder system with no pollution is very important. Animal glue is a non-toxic, biodegradable and water-soluble natural material and it can meet the environmental requirement mentioned above.However, the animal glue can not be used directly as a sand binder, because the original animal glue is solid-state at room-temperature and has a low activity, so it needs to be modified ${ }^{[2]}$. To improve the disadvantage of animal glue such as agglomeration at normal temperature, an alkaline decomposition process is used and optimized firstly. With the addition of a few active materials, the binder is modified by copolymerization and esterification. After modification the animal glue binder can be liquid at normal temperature and a high strength of binder can be built after been heated at $200^{\circ} \mathrm{C}$ for $20 \mathrm{~min}$.

\section{Experimental materials and methods}

\section{Raw materials}

The raw materials is as followed: animal bone glue, sodium hydroxide, glycerin, dextrin ,glycol, etc. The test devices include an ordinary device for synthesis, a viscosimeter, a mould for the sand sample's making, a SWY strength testing machine of sand, SEM ,etc.

\section{Experimental methods}

The preparation process of animal glue binder are as followed:

A certain amount of water and animal glue is mixed in a $500 \mathrm{ml}$ three-neck flask to swell for 30 minutes. Then catalyst is added in to decompose it. After a period of time, some modifiers are added into the flask. After a certain time of reaction, a kind of anticoagulants is added and then a yellow brown liquid binder has been made. 
The preparation of sand sample

At first , $1000 \mathrm{~g}$ of sand is mixed with $30 \mathrm{~g}$ binder for 2 minutes and the sand mixture is prepared to make 8-sized samples in the sample mold, the sand samples which been heated for a certain time are taken out to from baking oven ready for test. The room temperature was $25^{\circ} \mathrm{C}$ and the relative humidity was $60 \% \mathrm{RH}$.

The measurement of the tensile strength of sand samples

The tensile strength of sand samples is tested as main parameter, the initial strength $(\sigma 0)$ of compression strength is measured when the samples cool to room temperature and the final strength $(\sigma 24)$ is measured after 24 hours.

Characterization of the product structure

Been dried sufficiently, two samples of animal glue binder in which A is not modified and another B is modified were prepared and analyzed by an infrared spectrometer.

\section{Results and discussion}

The influence the ratio of animal glue to water on the strength of binder

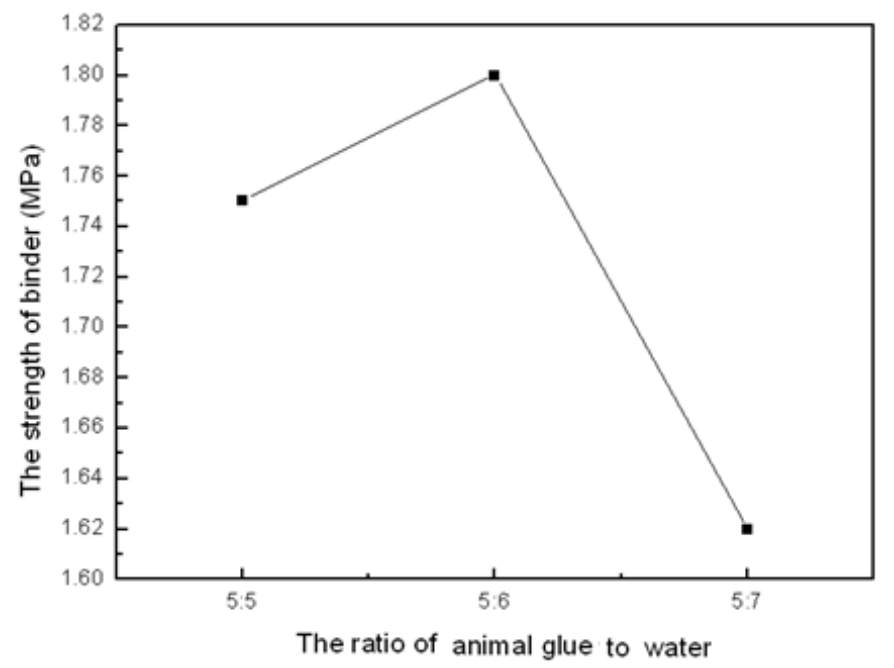

Fig. 1 Influence of the ratio of animal glue to water on the strength

With other conditions were fixed,the influence of the ratio of animal glue to water on the strength of the binder is shown in figure 1. It is found that a right ratio corresponds a high strength of binder. With more water in the binder can decrease the strength of binder and on the other hand, less water in the binder can increase the viscosity of the binder and can also decrease the strength of the binder. At last, the ratio of animal glue to water is chosen as 5:6.

The influences of the catalysts on the strength of the binder

Animal glue is a kind of macromolecule compound and under normal temperature it is easy to agglomerate, which bring some trouble to the use on foundry. By alkaline decomposition, the macromolecule of animal glue can be decomposed to smaller molecular, which is easier to be liquid at room temperature and apt to chemical reaction. It was found that alkali has a rapid decomposition speed and $\mathrm{NaOH}$ is chosen as the catalyst in the experiment. With other conditions were fixed,the influence of the amount of $\mathrm{NaOH}$ on the strength of the binder was shown in figure 2.

From figure 2,it is easy to see : the strength reaches a peak as the addition of $\mathrm{NaOH}$ is $5 \%$ to the amount of glue. With a less amount of $\mathrm{NaOH}$, the catalysis was not sufficient, the macromolecule of animal glues has not been decomposed completely, there are not enough active groups for next reaction. On the other hand, too much amount of $\mathrm{NaOH}$ could produce a large number of small hydrophilic molecules in the binder which also influenced the strength of the binder.Therefore, the proper amount of $\mathrm{NaOH}$ is $5 \%$ to the animal glue. 


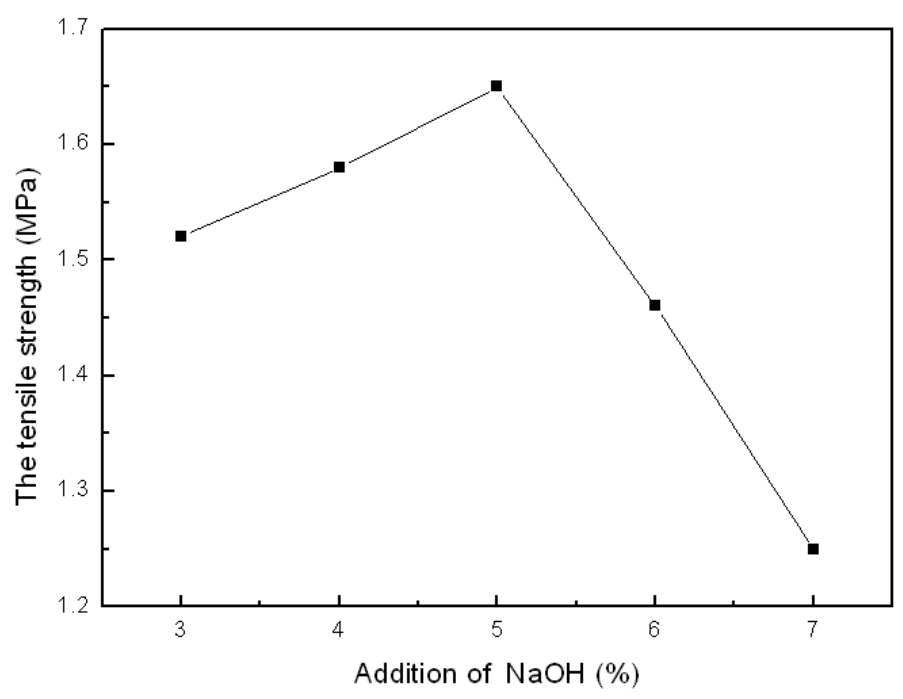

Fig. 2 Influence of the amount of $\mathrm{NaOH}$ on the binder

\section{The choice of modifiers and compound modification}

The molecules of animal glue are composed with large amino acid molecules in the peptide bond which is easy to agglomerate under room temperature. By alkaline decomposition, some of - $\mathrm{HN}-\mathrm{CO}$ structure can be disintegrated to amino(-NH2) and carboxyl (-COOH). And then copolymerization and the esterification can occur by the modification with the branched degree and the bonding strength increased.Glycerin, dextrin, glycol are selected as good modifiers . The design and level of each factor is shown in table 1 , the experiment result and the range analysis of them is shown in table 2 .

Table 1 Design of orthogonal factors and levels

\begin{tabular}{|l|l|l|l|}
\hline number & dextrin $(\%)$ & glycerin(\%) & glycol $(\%)$ \\
\hline 1 & 8 & 8 & 8 \\
\hline 2 & 10 & 10 & 10 \\
\hline 3 & 12 & 12 & 12 \\
\hline
\end{tabular}

Through the orthogonal test, the best ratio of them is determined as followed:animal glue :glycerin: dextrin: glycol = 100:10:10:10.

\section{Influence of reactive time of modification on the strength of binder}

The influence of reactive time of modification on the strength of the binder was shown in figure 3, with the others conditions remained the same.As the shown in figure 3 the final strength of binder looked like a mountain in the range of reactive time and the right reactive time is 90 minutes .During the course of modification, with a series of complex chemistry reaction have happened, a right reactive time can correspond a good distribution of large molecular of binder. 
Table 2 Results and analysis of orthogonal experiment

\begin{tabular}{|l|l|l|l|l|}
\hline number & $\begin{array}{l}\text { dextrin } \\
(\%)\end{array}$ & $\begin{array}{l}\text { Glycerin } \\
(\%)\end{array}$ & $\begin{array}{l}\text { glycol } \\
(\%)\end{array}$ & $\begin{array}{l}\text { strength(M } \\
\text { Pa })\end{array}$ \\
\hline 1 & A1 & B1 & C1 & 1.97 \\
\hline 2 & A1 & B2 & C2 & 1.83 \\
\hline 3 & A1 & B3 & C3 & 1.43 \\
\hline 4 & A2 & B1 & C2 & 2.56 \\
\hline 5 & A2 & B2 & C3 & 2.25 \\
\hline 6 & A2 & B3 & C1 & 2.28 \\
\hline 7 & A3 & B1 & C3 & 1.68 \\
\hline 8 & A3 & B2 & C1 & 2.40 \\
\hline 9 & A3 & B3 & C2 & 2.29 \\
\hline K1 & 5.23 & 6.21 & 6.65 & \\
\hline K2 & 7.09 & 6.48 & 6.68 & \\
\hline K3 & 6.37 & 6.00 & 5.36 & \\
\hline k1 & 1.74 & 2.07 & 2.22 & \\
\hline k2 & 2.36 & 2.16 & 2.23 & \\
\hline k3 & 2.12 & 2.00 & 1.79 & \\
\hline R & 0.62 & 0.16 & 0.44 & \\
\hline
\end{tabular}

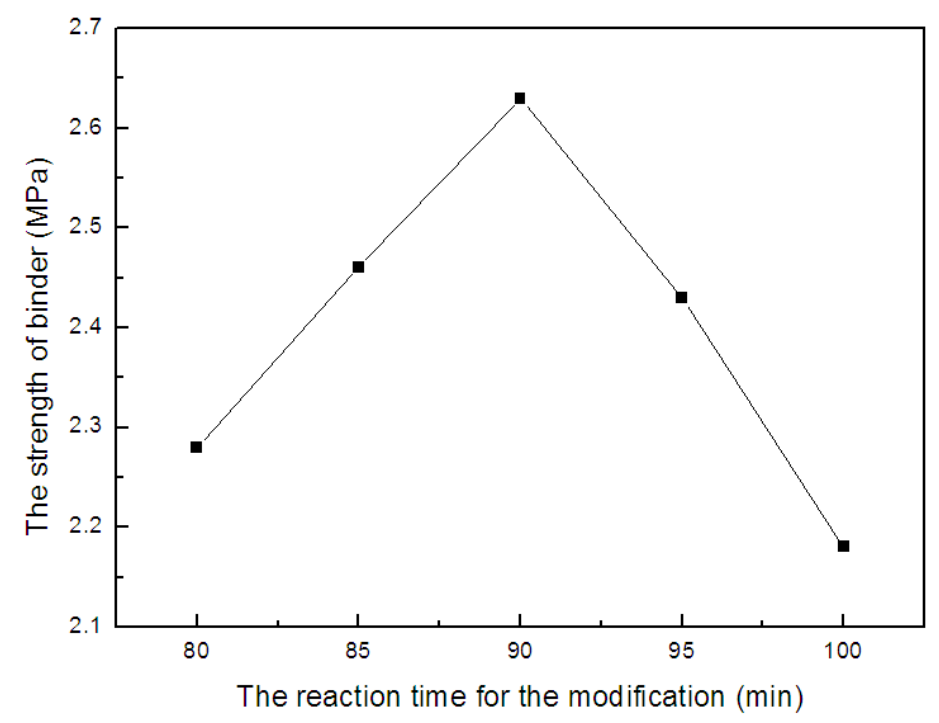

Fig.3 Influence of reactive time of modification on the strength of binder

\section{Influence of reactive temperature of modification on the strength of binder}

On the base of test of right reactive time, influence of reactive temperature of modification on the strength of binder is shown in figure 4, With the others conditions remained same. The strength of binder increases as the reactive temperature increases at first, reaches a peak, and then declines sharply. With the same reactive time, a right temperature also correspond a good distribution of large molecular of binder which could get a high binding strength. 


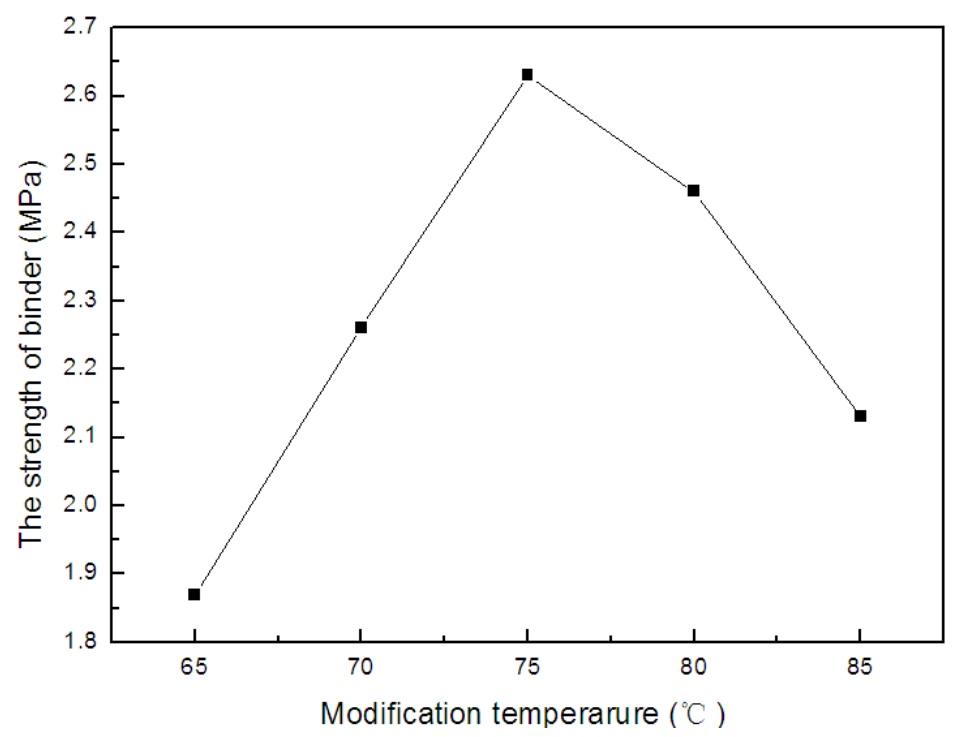

Fig.4 Influence of reactive temperature of modification on the strength of binder

\section{Characterization of the binder structure by IR}

Compared with an ordinary animal glue binder (curve A), the modified binder structure(curve B) is detected by IR as shown in figure 5 . The structure of the binder after the modification has been changed, which shows that animal glue macromolecular, after alkaline decomposition, grafting polymerization, esterification, has happened a series of chemical reactions. According to the infrared spectra, the absorption peaks near $1036 \mathrm{~cm}-1$ is the proof of asymmetric etherification reaction, which has been formed by hydroxyl dehydration. The absorption peaks near $1653 \mathrm{~cm}-1$ is the proof of the existence of carboxylic acid ester, which indicates that an esterification reaction happened between the carboxyl (-COOH) of animal glue macromoleculars and the carboxyl (-OH) of modifiers. The absorption peaks of (-NH-) near $3428 \mathrm{~cm}-1$ had changed strongly after modifications, which indicates that a graft copolymerization. occurred between the amidogen (-NH2) of animal glue macromoleculars and the carboxyl $(-\mathrm{OH})$ of modifiers.

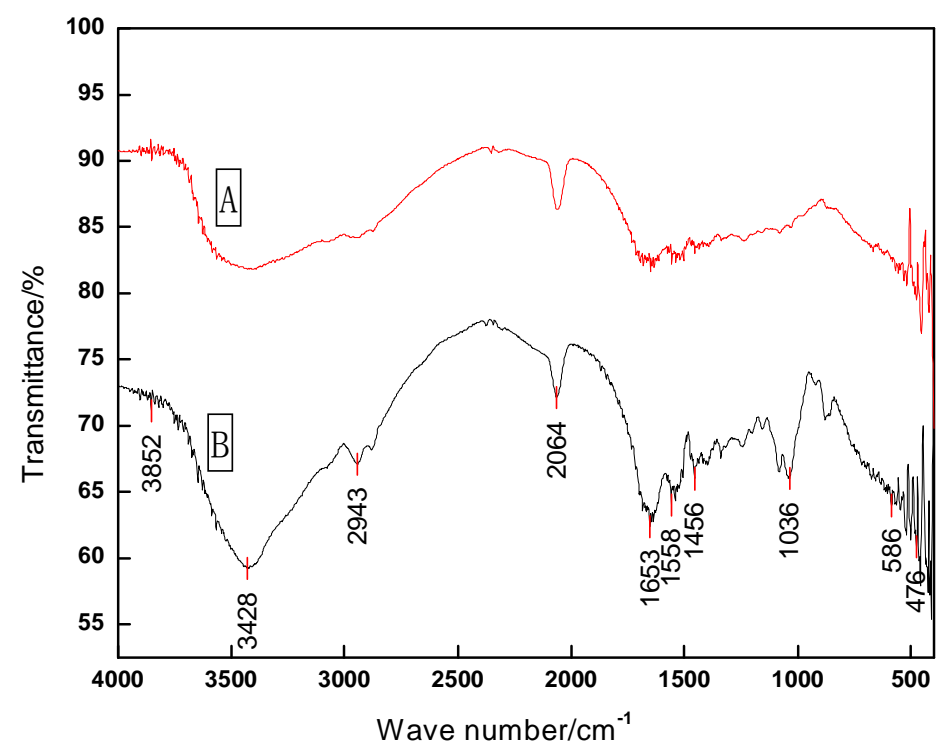

Fig. 5 Infrared spectra of the animal glue binder sand 


\section{Summary}

(1) A new modified animal glue binder which is liquid at room temperature and can be cured by baking has been prepared with an alkali decomposition,through the grafting copolymerization, an esterification reaction.

(2) In the alkaline decomposition, a good proportion between animal bone glue and water is selected as $5: 6, \mathrm{NaOH}$ is used as the catalyst and its addition is $5 \%$ to the amount of animal glue.

(3)The best ratio of the modifier is $\mathrm{m}$ (animal glue):m(glycerin): $\mathrm{m}$ (glycol): $\mathrm{m}\left(\right.$ dextrin): $=100: 10: 10: 10$, the modification reaction temperature is $75^{\circ} \mathrm{C}$ and the modification reaction time is 90 minutes.

(4) The sand with 3\% of binder can be cured by baking,the strength of sand can be $2.63 \mathrm{MPa}$.

(5)Through the analysis of the product by IR, The structure of the binder after the modification has been changed, which showes that animal glue macromolecular, after alkaline decomposition, grafting polymerization esterification and etherification, has happened a series of chemical reactions.

\section{Acknowledgements}

The research is supported by the National Natural Science Foundation of China (Grant No.51275313).

\section{References}

[1] Li Chuanshi. The present application and the development trend of domestic and foreign casting binder[J]. Casting, mechanical workers, 2004, (3):1-4.

[2]Li Aiju, Chen Hongyu. Research progress of environment friendly materials[M]. Research and application of materials, 2010, 4(4):372- 378.

[3]LV Dezhi, LUO Hao, XIE Huasheng, et al. Research on Graft Copolymerization of the Gelatin Binder for Foundry[J]. Foundry, 2006,55(7):678-682. 